\title{
Fungal inoculation induces agarwood in young Aquilaria malaccensis trees in the nursery
}

\begin{abstract}
Fungi are often used to induce agarwood in Aquilaria trees. This study was conducted to evaluate the effect of several fungi on agarwood formation over time in young Aquilaria malaccensis (Lam.) trees. Typical changes in the length and light intensity of the resulting discoloration were observed after three and six month periods following inoculation. Wood samples were observed microscopically and classified into several light intensity groups. The discoloration length was measured longitudinally. The duration after inoculation affected the mean of discoloration length: the 6-month old sample $(1.70 \mathrm{~cm})$ had a wider discoloration zone when compared to the 3-month old sample $(1.17 \mathrm{~cm})$. When measuring the discoloration intensity, a positive relationship with time was perceived. Digital images, captured using a camera-equipped microscope, revealed that wood samples collected after six months appeared to be 1.8-times darker than after three months. We concluded that time, not the species of any of the tested fungi, had significant effect on discoloration length and intensity. Gas chromatography/mass spectrometry (GCMS) analysis of the 6-month old sample yielded some important agarwood compounds such as benzylacetone, anisylacetone, guaiene and palustrol. This demonstrates that the tested fungi have the ability to induce agarwood formation in nursery A. malaccensis trees.
\end{abstract}

Keyword: Artificial inoculation; Discoloration zone; Fungi; Guaiene; Palustrol 